\title{
Intrinsic Healable and Recyclable Thermoset Epoxy Based on Shape Memory Effect and Transesterification Reaction
}

\author{
Lu Lu, Jizhou Fan, Guoqiang Li* \\ Department of Mechanical \& Industrial Engineering \\ Louisiana State University \\ Baton Rouge, LA 70803, USA
}

Tel.: 001-225-578-5302

Fax: 001-225-578-5924

E-mail: lguoqi1@1su.edu 


\begin{abstract}
A shape memory and healable epoxy was prepared based on esterification between diglycidyl ether of bisphenol A and tricarballylic acid. The healing was achieved through transesterification at the fracture surface between two epoxy blocks in a confined space assisted by shape recovery force. The shape recovery of the compression programmed epoxy at elevated temperature tightly closed the gap between the two epoxy blocks, whose fracture surfaces are saw-cut and not perfectly matched during healing, which is the worstcase scenario for the healing test. A healing efficiency of $\sim 60 \%$ was achieved. This suggests that, for naturally cracked surfaces, which have smoother fracture surfaces and better surface alignments during healing, higher healing efficiencies could be expected. We believe that the combination of shape memory and intrinsic healing capability within one network will broaden the applications of thermosets and enable recycling.
\end{abstract}

Key words: Healable polymer, shape memory polymer, dynamic covalent bond, transesterification, epoxy, recycle 


\section{INTRODUCTION}

Thermosets are permanently cross-linked polymers which cannot be remolded or reprocessed once the curing reaction is complete. They have superior properties such as good mechanical strength, thermal and dimensional stability, and environmental resistance. Thermosets are irreplaceable in some applications, including lightweight structures, high performance coatings, and adhesives. However, thermoset is generally not recyclable, which represents a grand challenge for sustainability and greener society.

The introduction of dynamic covalent chemistry [1], such as materials containing alkoxyamines [2], hydrogen bonding [3], Diels-Alder adducts [4], nucleophilic addition between isocyanate and imidazole [5], carbene dimerization [6], and so on, established a feasible strategy for the healing of thermosets so that the thermosets can be recycled [711]. For example, a temperature sensitive polymerization-depolymerization equilibrium was achieved with a Diels-Alder adducts network [12]. The network with a furan-based diene and a maleimide-based dienophile, favors low-temperature network formation and high-temperature depolymerization. The healing is achieved by matching the crack surfaces as close as possible and holding together with the help of a compressive load at high temperatures. Therefore, healable and recyclable thermoset polymers are realized.

However, most healable/recyclable thermoset systems require multi-step synthesis and manually holding the fracture pieces together, which limit their widespread applications. We realized that the chemistries involved in preparing thermoset epoxies are straightforward. The curing process requires mixing hardeners (usually amines) with epoxy pre-polymers at selected curing temperatures to afford epoxy thermosets. The tensile strength, compressive strength, modulus, and thermal transition temperature can be easily 
tuned in a broad range by varying the formulation because of the existence of a variety of pre-polymers with diverse structures, molecular weights, and thermal transition temperatures (e.g. glass transition temperature). Furthermore, for epoxy based shape memory polymers, the shape recovery ratio can reach $98-100 \%$ [13-14]; some systems own multishape memory effect [15]; and the elastic modulus of the materials can approach several GPa. Such outstanding features make epoxy one of the most studied systems in thermoset polymers [16].

Regarding the healing of epoxy thermoset, incorporating microencapsulated healing agent and catalyst within epoxy is the most popular method [17-19]. For example, dicyclopentadiene healing agent and Grubb's first generation $\mathrm{Ru}$ catalyst [20], ureaformaldehyde micro-capsules and $\mathrm{CuBr}_{2}$ latent hardener epoxy [21] and its hardener mercaptan [22-23], poly(dimethylsiloxane) resin and organotin catalyst [24], diluted epoxy monomer and modified aliphatic polyamine [25], and so on [26-31], were incorporated in the epoxy networks and investigated for their efficiencies in crack healing. The self-healing process is triggered by releasing the healing agent into the crack volume once the material is damaged. Another economical and simple method of healing epoxy crack is encapsulating solvents in the polymer matrix [32]. Leng et al fabricated a shape memory and healable epoxy composite by uniformly distributing poly( $\varepsilon$-caprolactone) (PCL) fiber in the epoxy matrix [33]. The PCL mat filler is melted when the temperature of the specimen is above the melting point of the PCL, which leads to recovery to the original condition of the PCL. The volume expansion of the PCL leads to pressure in the epoxy matrix, which pushes the PCL liquid into the crack to heal the damage. 
Researchers have discovered an even simpler way to achieve healing of epoxy thermoset without additional microencapsulated healant/catalyst/hardener [34-36]. Leibler et al. designed an epoxy network that can rearrange its topology by exchange reactions without depolymerization, and showed that they are insoluble and processable [34]. Later on, Leibler et al. compared the transesterification for healing and assembling thermosets with and without catalysts $[35,37]$. The crack healing event of the epoxy was achieved by transesterification reaction within the network at elevated temperature by manually bringing the crack surfaces in contact [38-39]. Qi et al. demonstrated in their molecular dynamics study that the closer the initial gap between the fracture surfaces, the faster the healing process and the higher the healing efficiency [39]. However, most of the above systems require manually closing the gap between the fracture surfaces before healing can occur. We believe that such healing approach represents a grand challenge in real-world structures because manually bringing fracture surfaces in contact in load carrying structures is a challenging job [40]. Li indicated that a combination of shape memory effect and intrinsic healing capability in a single thermoset network would be a way of overcoming this challenge [40]. This vision was based on the two-step biomimetic close-then-heal (CTH) strategy [41-42]. In this study, we would like to incorporate the shape memory effect of epoxy into its healing process so that healing can proceed with minimal external aid. To the best of our knowledge, this has not been reported in the literature.

\section{MATERIALS AND METHODS}

\subsection{Polymer synthesis}

Diglycidyl ether of bisphenol A (DGEBA), tricarballylic acid, and tetrahydrofuran (THF) were purchased from Sigma-Aldrich (St. Louis, MO, USA) and used to prepare 
healable epoxy without further purification. $38.3 \mathrm{~g}(0.113 \mathrm{~mol})$ DGEBA and $12.9 \mathrm{~g}(0.073$ mol) tricarballylic acid (chemical structures shown in Figure 1) were added into $40 \mathrm{~mL}$ THF. The molar ratio between ethylene epoxide from DGEBA to - $\mathrm{COOH}$ in tricarballylic acid is $\sim 1: 1$ so that the maximum transesterification efficiency can be achieved [43]. The mixture was stirred and sonicated for $10 \mathrm{~min}$, followed by heating to $80{ }^{\circ} \mathrm{C}$ to speed up the esterification reaction. The amount of white solid tricarballylic acid was slowly decreasing in THF with the proceeding of the reaction between DGEBA and tricarballylic acid. The mixture was then kept at $100{ }^{\circ} \mathrm{C}$ until all THF was evaporated. After that, the sticky liquid was poured into a PTFE mold or aluminum foil mold and cured at $130{ }^{\circ} \mathrm{C}$ for $5-6 \mathrm{~h}$, following the established procedure $[38,44]$. The heating of the oven was then turned off, allowing slowly cooling down of the prepared epoxy overnight. A piece of transparent yellow solid was obtained. The curing temperature of $150{ }^{\circ} \mathrm{C}$ was also used to compare the degree of curing with epoxy cured at $130{ }^{\circ} \mathrm{C}$.

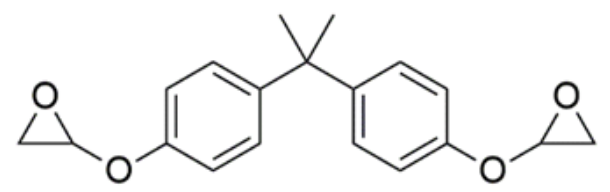

Diglycidyl ether of bisphenol A (DGEBA)

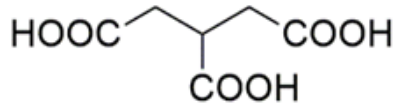

Tricarballylic acid

Figure 1. The chemical structures of the two reagents to prepare the healable epoxy.

\subsection{Thermomechanical and compositional characterizations}

Differential scanning calorimeter (DSC) studies were conducted using model DSC 4000 by PerkinElmer (MA, USA). A small piece of as-prepared epoxy of about $7 \mathrm{mg}$ was placed in an aluminum pan and scanned between $-20{ }^{\circ} \mathrm{C}$ and $160{ }^{\circ} \mathrm{C}$ with heating and cooling rates of $10{ }^{\circ} \mathrm{C} / \mathrm{min}$. The purging rate of the nitrogen gas is $30 \mathrm{~mL} / \mathrm{min}$. Two cooling and heating cycles were conducted. The second heating cycle was used to acquire the glass 
transition temperature $\left(T_{g}\right)$. Thermal gravity analysis (TGA) was carried out on a TA 2950 TGA (TA Instruments, DE, USA) under nitrogen atmosphere with a heating rate of $10{ }^{\circ} \mathrm{C} / \mathrm{min}$. The scanned temperature range was $30-600{ }^{\circ} \mathrm{C}$. The data was analyzed with Thermal Advantage Software. Dynamic mechanical analysis (DMA) was conducted in the multi-frequency-strain mode using model Q800 DMA (TA Instruments, DE, USA). The amplitude was $15 \mu \mathrm{m}$, the frequency was $1 \mathrm{~Hz}$, and the temperature sweep range was -20 to $100{ }^{\circ} \mathrm{C}$. The temperature ramp rate was $3{ }^{\circ} \mathrm{C} / \mathrm{min}$. The chemical composition of the asprepared epoxy was characterized with Bruker Alpha FTIR Spectrometer with the scan range of $4000-400 \mathrm{~cm}^{-1}$.

\subsection{Fracture specimen preparation and surface characterization}

The cured epoxy specimen of $50 \mathrm{~mm} \times 20 \mathrm{~mm} \times 10 \mathrm{~mm}$ was firstly cut into two pieces using a band saw. The saw-cut rough epoxy surface was not polished so that the healing will be subjected to the worst case scenario, i.e., poor alignment and contact between the fracture surfaces. The saw-cut epoxy surface and the fracture surface created during the ultimate compressive strength test were visualized with Scanning Electron Microscopy (SEM) (Quanta 3D FEG, Hillsboro, OR) using secondary electrons. The sample surfaces were coated with platinum for about $6 \mathrm{~nm}$. The accelerating voltage was $5 \mathrm{kV}$ and the working distance was 9-9.5 $\mathrm{mm}$.

\subsection{Stress memory and shape memory tests}

Based on the close-then-heal (CTH) strategy [40-42], the specimens need to be compression programmed, in order to use constrained shape recovery (constrained volume expansion) to close the cracks within the specimen. The shape recovery force generated from the shape memory effect of the epoxy will be the internal stress to push the fracture 
surfaces marching towards each other. Therefore, it is necessary to investigate its stress memory and shape memory effect by running the thermomechanical cycle test. The traditional hot programming was conducted by the eXpert 2610 MTS (ADMET, Norwood, MA, USA). The control software is MTESTQuattro. The temperature in the thermal chamber is controlled by E5AC-T digital controller (OMRON, Japan). The programming process started with increasing the temperature to $120{ }^{\circ} \mathrm{C}$ at a rate of $10{ }^{\circ} \mathrm{C} / \mathrm{min}$. The asprepared epoxy specimen was then compressed to $10 \%$ pre-strain, at a loading rate of 1 $\mathrm{mm} / \mathrm{min}$. The specimen was then slowly cooled down to room temperature (below the $T_{g}$ region) by maintaining the pre-strain. After that, the load was removed, completing the compression programming process. In order to investigate the stress memory of the epoxy, fully constrained stress recovery test was conducted by gradually increasing the temperature of the epoxy specimen to $120^{\circ} \mathrm{C}$ and holding the temperature for 5 min until the recovery stress was stabilized. A visual inspection of the shape memory effect by free shape recovery of the epoxy was also conducted.

\subsection{Compressive strength test}

In order to investigate the compressive strength of the as-prepared specimens, isothermal uniaxial compression test was conducted. The compression test was conducted using the MTS machine (Alliance RT/5, MTS, USA) equipped with a temperature regulated oven controlled by Eurotherm controller (Thermodynamic Engineering Inc. Camarillo, CA). Several temperatures were selected, from glassy to rubbery temperatures, in order to fully understand the compression behavior of the healable epoxy. The loading rate was $1 \mathrm{~mm} / \mathrm{min}$ for all the specimens. 


\subsection{Cold programming and self-healing test}

To conduct self-healing test, the as-prepared epoxy was firstly cut in half using a band saw as shown in Figure 2a, followed by a compression programming to each piece of the epoxy to induce shape change and store some internal energy (Figure 2b). The compression programming was conducted in air at room temperature since cold programming at glassy state has been proved to be as effective as hot programming in rubbery state [45], but with much reduced programming time and without the need for thermal management. The cold uniaxial compression programming was conducted by the MTS machine at room temperature. The loading rate was $1 \mathrm{~mm} / \mathrm{min}$. The specimens were compressed to two pre-strain levels of $3.0 \%$ and $8.5 \%$, and maintained the pre-strain for 10 min. After that, the specimens were unloaded, completing the cold compression programming. The shape fixity ratios for the two pre-strain levels, which were measured immediately after removing the programming load, were $98.2 \%$ and $98.5 \%$, respectively. A typical stress versus time relationship during cold compression programming by $8.5 \%$ pre-strain is shown in Figure 2d. It is noted that, while the pre-strain levels were not beyond the yielding point (about $12 \%$ as will be shown in Figure 5a), the cold programming still fixed a certain stress, due to the 10 min stress relaxation step. As indicted in the literature [40], stress relaxation is also a way of storing or memorizing stress in SMPs. In particular, the compressive stress (or energy input) activated the dynamic covalent bond network at glassy temperature and made it easier for the programming stress to overcome the coordinated segmental rotation resistance, which was similar to lowering the yield threshold and thus facilitated storing a certain stress. After compression programming, the longitudinal length is reduced and the transverse width is increased, as seen in Figure $2 b$. 
The reason to cut the as-prepared specimen to half and conduct programming individually was to avoid buckling during programming. The large slenderness ratio of the as-prepared specimen caused buckling during cold compression programming.

During healing of the cold programmed specimens, the two pieces of cut and programmed epoxy specimens were stacked in a confined space (i.e., in between the two crossheads of the MTS machine in our experiment), immediately after programming and without applying external load. When elevating the temperature of the oven to the designed level $\left(120^{\circ} \mathrm{C}\right.$ and $150{ }^{\circ} \mathrm{C}$ in this study), the constrained shape recovery of the epoxy closed the gap between the two blocks, due to the release of the stored compressive stress. The tight contact between the two fracture surfaces enabled the healing process by transesterification reaction. Two healing time periods were used, $18 \mathrm{~h}$ and $52 \mathrm{~h}$, to investigate the effect of healing time on the healing efficiencies. Figure $2 \mathrm{c}$ shows the healed specimen.

(a) Before compression

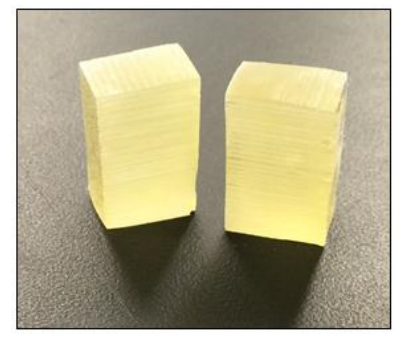

(b) After compression

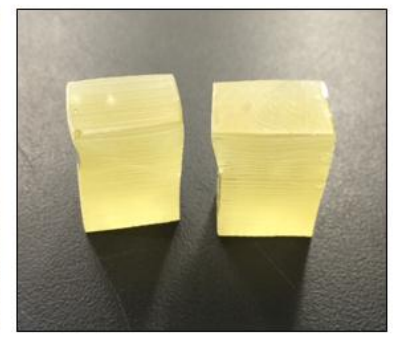

(c) After healing

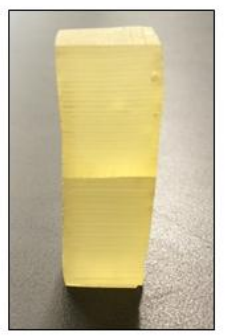

(d) Programming Profile

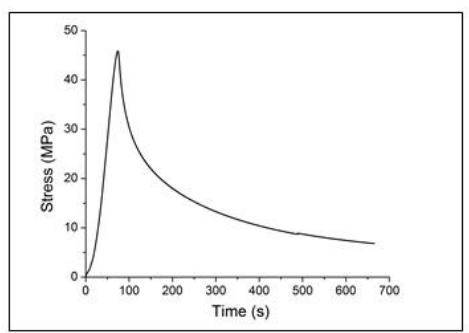

Figure 2. Typical photos of epoxy specimens before compression programming (a), after compression programming (b), after healing (c), and (d) typical stress versus time during cold compression programming.

\subsection{Healing efficiency test}

The healing efficiencies were determined by uniaxial tension test. The healed specimens were tensile tested using eXpert 2610 MTS (ADMET, Norwood, MA, USA). The tests were conducted at room temperature at a loading rate of $1 \mathrm{~mm} / \mathrm{min}$ until fracture. The ratio of the tensile strength of the healed specimen over the tensile stress at the crack 
initiation point of the original undamaged (as-prepared) specimen was defined as the healing efficiency.

\section{RESULTS AND DISCUSSION}

\subsection{Characterizations of as-prepared healable epoxy}

The as-prepared healable epoxy was characterized by DSC (Figure 3a), TGA (Figure 3b), DMA (Figure 3c), and FTIR (Figure 3d). DSC studies with two heating and cooling cycles were conducted between -20 to $160{ }^{\circ} \mathrm{C}$ (Figure $3 \mathrm{a}$ ). The second heating cycles of epoxies cured at 130 and $150{ }^{\circ} \mathrm{C}$ are shown in the figure so that the thermal history of the material can be eliminated in the first cycle. The glass transition temperatures $\left(T_{g}\right)$ of the epoxies cured at different temperature are around $57-59{ }^{\circ} \mathrm{C}$ as labeled in Figure $3 \mathrm{a}$. The similarity in the $\mathrm{T}_{\mathrm{g}}$ between the two curing temperatures indicates that $130{ }^{\circ} \mathrm{C}$ is sufficient to cure the system.

The thermal stability of the healable epoxy was examined by TGA (Figure 3b) in the temperature range of 30 to $600{ }^{\circ} \mathrm{C}$. We could see that the decomposition temperature (onset temperature of the weight loss peak) of the epoxy cured at $130{ }^{\circ} \mathrm{C}$ is about $383{ }^{\circ} \mathrm{C}$. This shows that the epoxy is stable during the healing process (maximum temperature of $\left.150^{\circ} \mathrm{C}\right)$.

The healable epoxy was also scanned by DMA for its thermomechanical property in the temperature range of -20 to $100{ }^{\circ} \mathrm{C}$ (Figure $\left.3 \mathrm{c}\right)$. The glass transition temperatures of the material are labeled on the basis of the onset of storage modulus, peak of loss modulus, and peak of tan delta. There is a slight difference between the three $T_{g}$ values, which is a common phenomenon. The storage modulus of the epoxy is $2.6 \mathrm{GPa}$ at $25^{\circ} \mathrm{C}$ and it quickly drops to $161 \mathrm{MPa}$ at $60{ }^{\circ} \mathrm{C}$, which indicates good shape memory capability. 
The ester carbonyl stretch analyzed by FTIR at $1728 \mathrm{~cm}^{-1}$ is labeled in Figure 3d, which proves the success of the esterification reaction. The other characteristic peaks labeled in the plot are: $3388 \mathrm{~cm}^{-1}$ (O-H stretch), 2959, 2927 and $2870 \mathrm{~cm}^{-1}$ (C-H stretch), $1508 \mathrm{~cm}^{-1}$ (aromatic C-C stretch), 1234, 1180 and $1035 \mathrm{~cm}^{-1}$ (ester C-O stretch), and 827 $\mathrm{cm}^{-1}$ (out of plane deformation of para-substituted benzene).
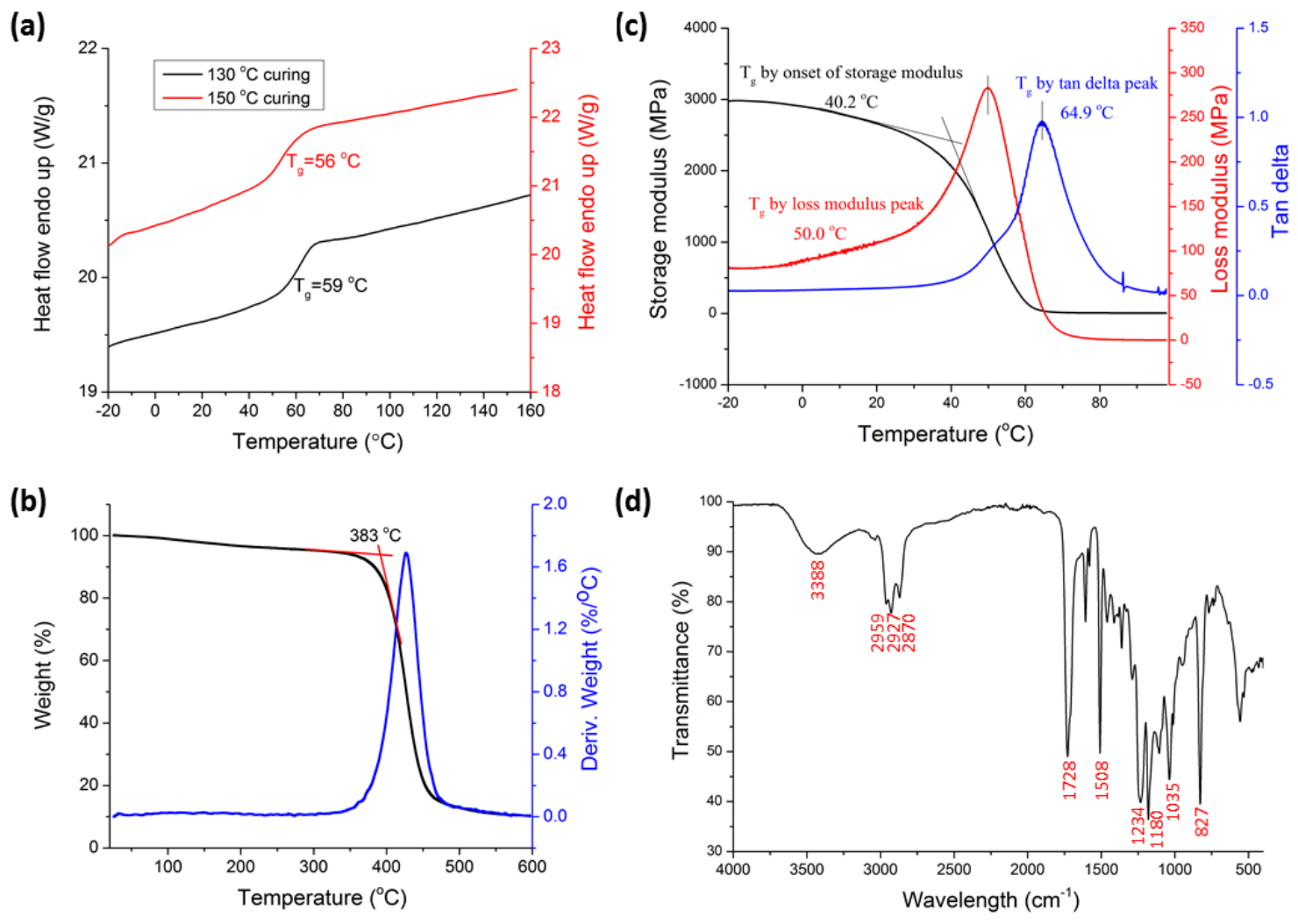

Figure 3. Characterizations of the self-healing epoxy using DSC (a), TGA (b), DMA (c), and FTIR (d).

\subsection{Stress memory and shape memory}

The thermomechanical cycle of the epoxy is shown in Figure 4. The compressive stress is $2.3 \mathrm{MPa}$ when the strain reaches $10 \%$ in Step 2. The recovery force was measured and it recovered to $1.9 \mathrm{MPa}$ after heating the material to $120{ }^{\circ} \mathrm{C}$; see Step 5. Clearly, this recovery stress will be utilized to close the crack during the healing process. For shape memory, a visual inspection of the shape memory effect was conducted by free shape 
recovery test of the epoxy, which is shown in the supporting information Video S1. A quick recovery (1-2 s) with $100 \%$ shape recovery ratio was achieved.

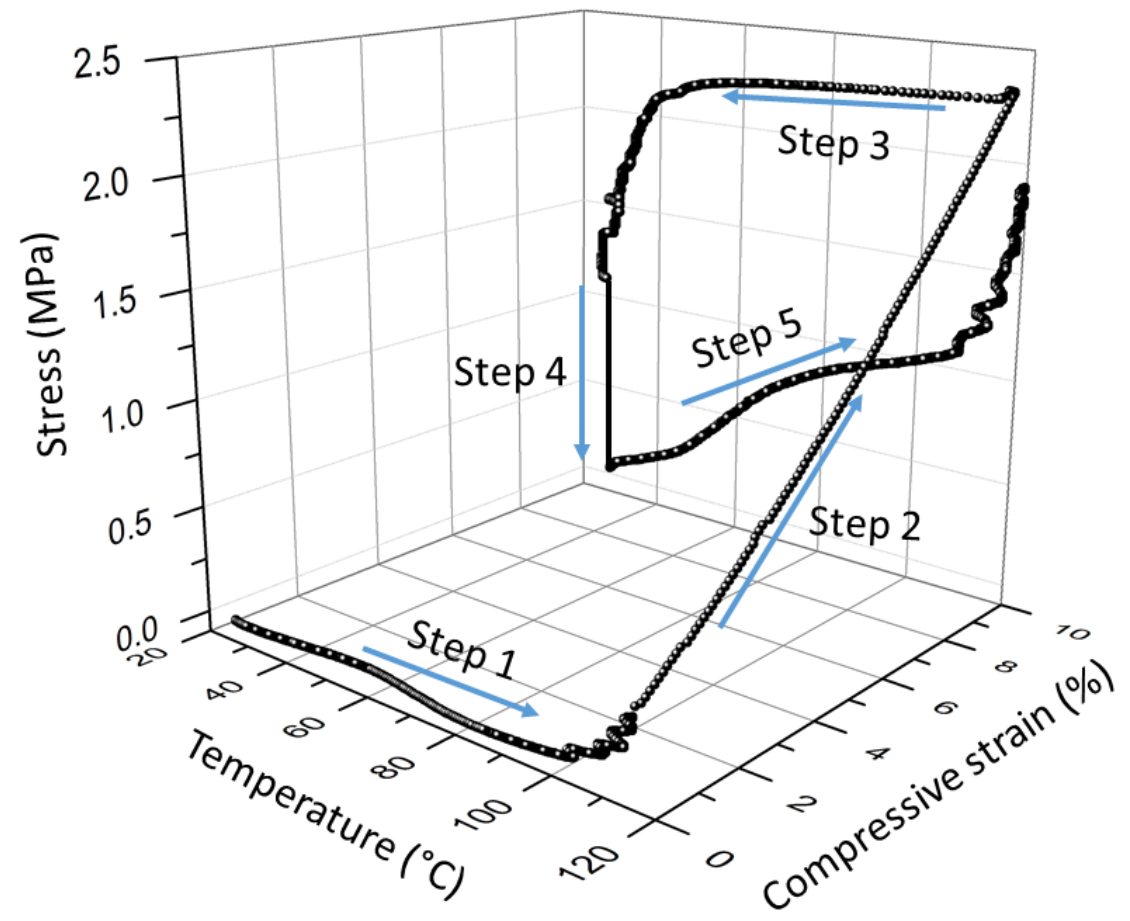

Figure 4. Five-step thermomechanical cycles for the shape-memory epoxy. 1) Heating. 2) High temperature loading. 3) Cooling. 4) Unloading. 5) Fully constrained shape recovery or stress recovery.

\subsection{Compressive Strength}

The ultimate compressive strength of the epoxy at room temperature is shown in Figure 5a. The compressive stress was increasing with the compression strain till $12 \%$ strain, i.e., yielding. Then, strain softening occurs, followed by plastic flow and finally strain hardening. This is very typical for shape memory polymers compressed at glassy temperature [41-43]. With the proceeding of the compression process, small cracks were continuously generated inside the specimen but the specimen did not break into pieces. At $61 \%$ strain, there was a big drop in compressive stress because a large crack was generated within the specimen. However, the specimen was still held together as shown in Figure 5c 
and was able to be further compressed as shown in Figure 5a. The compressive strength of the epoxy is $213 \mathrm{MPa}$ at $61 \%$ strain and the modulus is $1.3 \mathrm{GPa}$. Then, we visualized the shape recovery process of this compressed (cold-programmed) specimen by directly putting the material in a $120{ }^{\circ} \mathrm{C}$ oven. The specimen was $100 \%$ recovered to its original shape. However, during the recovery process, we saw a piece of the epoxy peeled and flied away from its main body, i.e. spalling, which is probably due to the fast expansion (recovery) of the compressed specimen and thus ejects a surface piece away. This indicates that, in order to recycle the fractured epoxy through shape recovery and intrinsic healing, it needs to be held in a confined space. With the healing experiment which will be discussed later, we need the specimen to be confined externally to achieve crack closing and healing. For real-world large load carrying structure, local heating around the crack can be conducted, and the surrounding "cold" materials can provide the needed external confinement [46]. Furthermore, architectural design of composite structures can also intrinsically provide the required confinements such as sandwich skin [47], grid skeleton [48], and 3-D woven fabric [49]. Therefore, for healing wide-opened cracks or recycling, the only human intervention needed is to locally heat the structure to the healing temperature. It is noted that, while some "self-healing" strategies do not explicitly require heating, such as extrinsic healing by incorporation of liquid heating agent, heating do increase the healing efficiency and reduce the healing time [50].

The ultimate compressive strengths at temperatures of $60,90,120$ and $150{ }^{\circ} \mathrm{C}$ were tested and shown in Figure 5b. We can see that the ultimate strain levels of compression at break are decreasing with the increase in temperature, with $36 \%$ at $60{ }^{\circ} \mathrm{C}, 28 \%$ at $90{ }^{\circ} \mathrm{C}$, $26 \%$ at $120{ }^{\circ} \mathrm{C}$, and $20 \%$ at $150{ }^{\circ} \mathrm{C}$. The ultimate compressive strengths are in the range 
of 2.8 to $5.0 \mathrm{MPa}$ at elevated temperatures (Figure $5 \mathrm{~b}$ ), which are significantly smaller than the compressive strength at room temperature (213 MPa). We believe that this is due to the dynamic nature of the ester bonds in the epoxy at elevated temperatures. The reversible reactions of the ester bonds forming and breaking (transesterification reaction) were speeded up at elevated temperatures. The ester bonds breaking sites were the weak points during compression. This was why at higher temperatures, the dynamic ester bonds exchanged quicker and the materials broke into smaller pieces $\left(90,120\right.$ and $150{ }^{\circ} \mathrm{C}$ in Figure 5d). However, at room temperature, the reactivity of the dynamic exchange of the ester bonds was very low so that the material kept holding together with multiple cracks generated upon loading (Figure 5c). Therefore, on the basis of this study, we know that we cannot excessively compression program the epoxy during hot programming since the material can only withstand 2.8 to $5.0 \mathrm{MPa}$ stress at elevated temperatures $\left(60-150{ }^{\circ} \mathrm{C}\right)$. From section 3.2, we know that the maximum recovery stress at $120^{\circ} \mathrm{C}$ is $1.9 \mathrm{MPa}$, which is smaller than the compressive strength at $120{ }^{\circ} \mathrm{C}$ (about 5.0 MPa), suggesting that the recovery stress helps close the crack but not cause fracture of the specimen.

\subsection{Healing}

In previous healing studies on intrinsic healable polymers, the wide-opened cracks or fractured specimens were firstly closed by hand before the healing event. In our design, the crack closing process was accomplished by the material itself through constrained shape recovery and the healing was achieved intrinsically. Obviously, this is different from the existing intrinsic healing epoxy [35, 38-39], and also different from previous thermoset shape memory polymers, which need incorporation of healing agent [51,52]. 
(a)

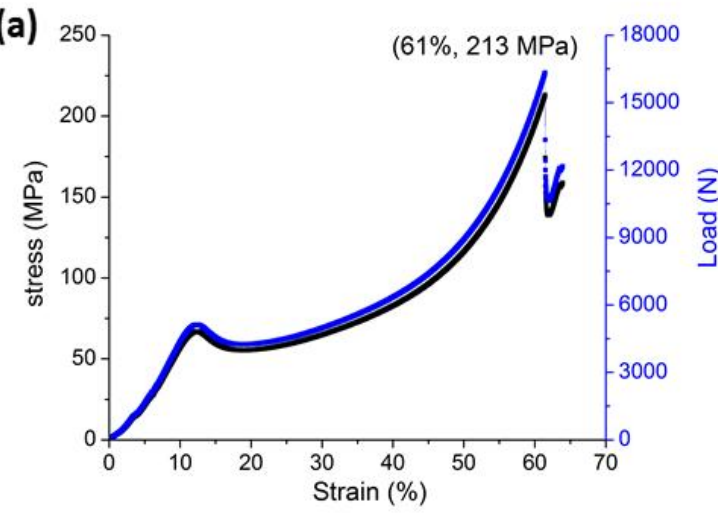

(b)

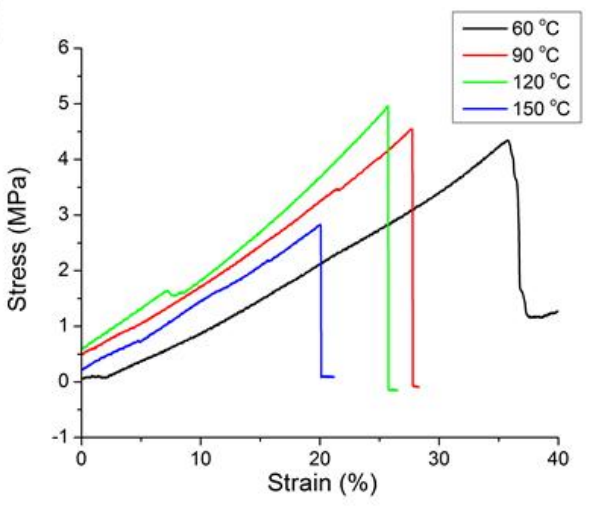

(c)

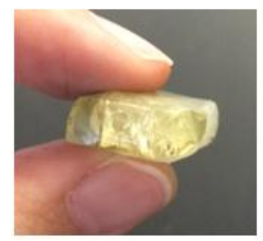

$25^{\circ} \mathrm{C}$ (d)

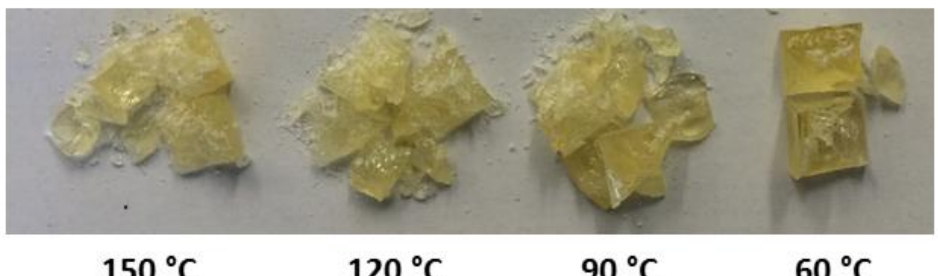

Figure 5. Compression behaviors of the prepared epoxies under room (a) and elevated temperatures (b). The appearances of the epoxy after compression until break at room and elevated temperatures are shown in (c) and (d), respectively.

The healing process of the thermoset epoxy in the confined space with transesterification reaction was illustrated in Figure 6. The tricarballylic acid containing three functional groups and DGEBA with two functional groups can form a cross-linked thermoset network. The two networks of the two epoxy blocks in the confined space are illustrated using different colors for clear expression. There existed a millimeter or submillimeter gap between the two epoxy blocks since no external load was applied. With this large crack opening, transesterification reaction could not proceed since the distance between the molecules were not close enough. The internal shape recovery force of the two epoxy blocks at elevated temperature closed the gap between them and enabled the transesterification reaction. Of course, there was a slight shape recovery in the transverse direction because the sides of the specimen were free. Therefore, the width of the specimen after healing was a little bit smaller as demonstrated in Figure 6. The ester bonds at the 
contact area underwent dynamic exchange reaction (i.e. transesterification reaction) and the two blocks were welded by themselves without external load, or with recovered stress only. Leibler et al found that in their system, transesterification reaction took $15 \mathrm{~h}$ at $150{ }^{\circ} \mathrm{C}$. With catalyst (zinc acetate), the exchange time can be greatly reduced. We choose not to add catalyst in our system because: 1) the immiscibility of catalyst zinc acetate with our system; and 2) we want to simply focus on the efficiency of the healable epoxy through transesterification without other interferences.

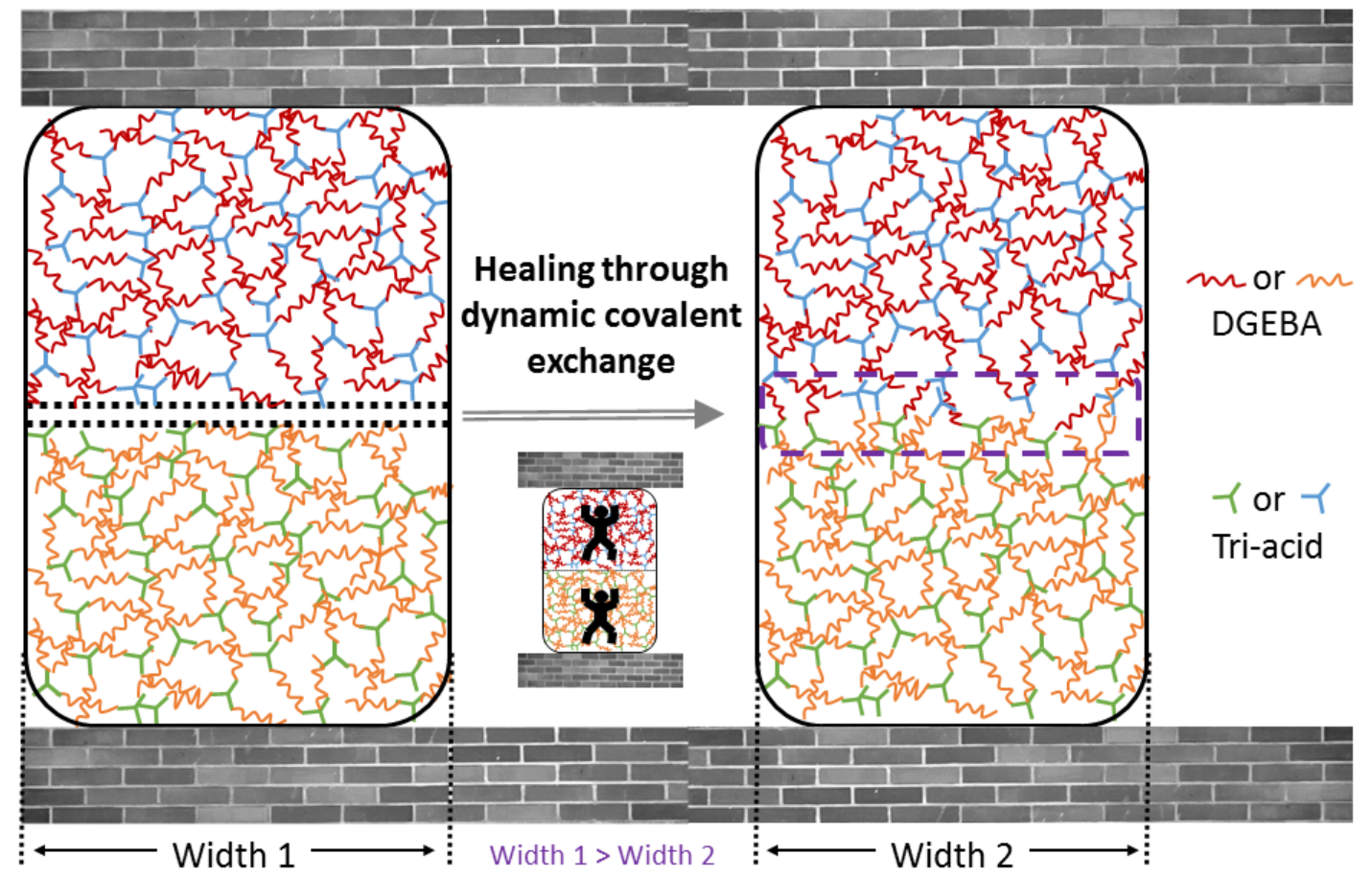

Figure 6. Experimental design and demonstration of the dynamic exchange of the ester bonds at the contact area.

\subsection{SEM observation}

Since the healing experiment was proceeded between two saw-cut surfaces, the micron scale morphology of the cut surface needs to be considered. In the zoomed-out view of the saw-cut surface (Figure 7a), the roughness of the surface can be clearly visualized. In the zoomed-in view (Figure 7b), we can see a large amount of particles with various 
sizes on the saw-cut epoxy surface, even though the SEM samples were carefully brushed and rinsed with water. In comparison, a small fracture piece from $120{ }^{\circ} \mathrm{C}$ compression test was also characterized with SEM at the same magnification levels as the saw-cut surface. Much smoother surfaces with sharp fracture edges can be seen in Figures $7 \mathrm{c}$ and $7 \mathrm{~d}$. This suggests that the saw-cut specimens used in this study are the worst case scenario. The naturally occurred smooth facture surface facilitates contact and alignment and thus enhances healing efficiency.

(a)

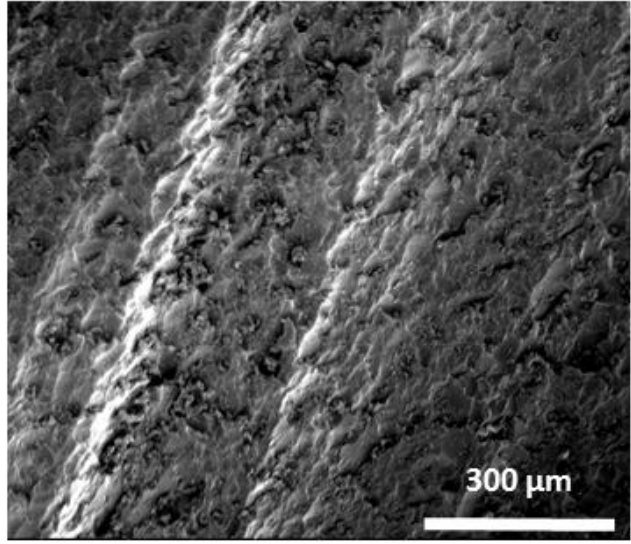

(c)

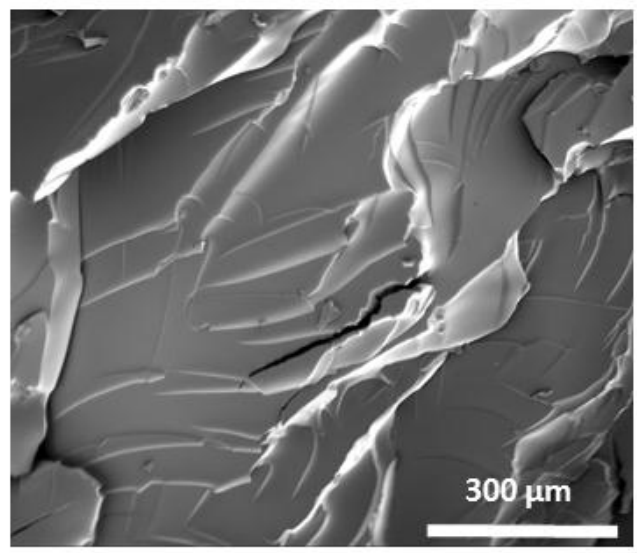

(b)

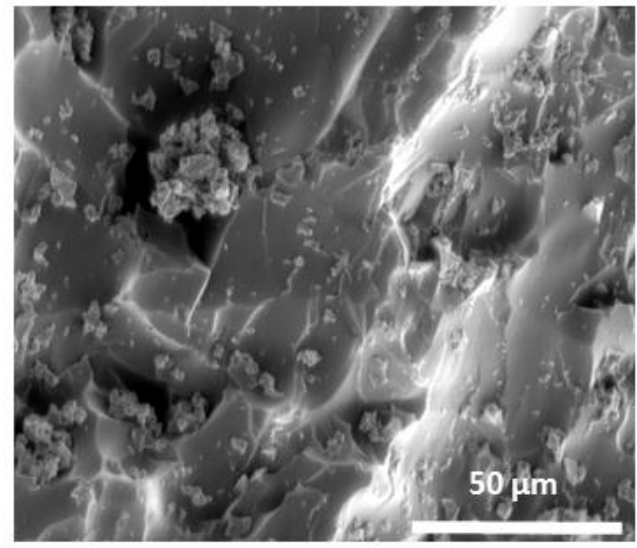

(d)

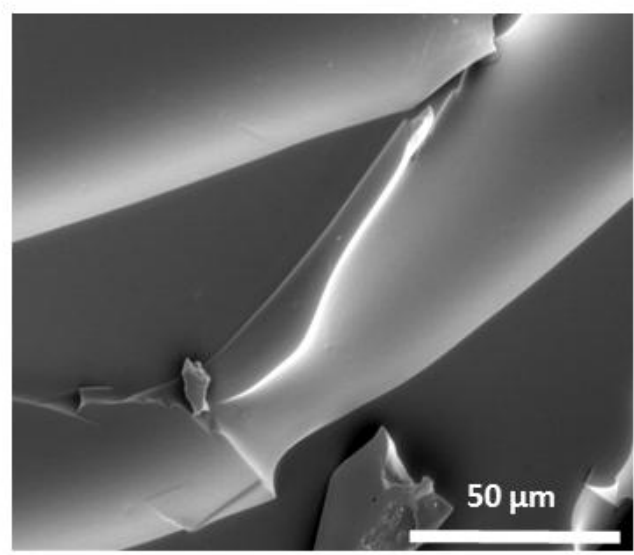

Figure 7. SEM images of saw-cut epoxy surfaces ( $a$ and $b$ ) and fracture surfaces after compression (c and d).

\subsection{Healing efficiency}

Tensile tests were conducted on the as-prepared epoxy specimen and the healed ones (Figure 8). For the as-prepared epoxy (Figure 8a), the tensile stress increased quickly 
with the extension of the specimen to reach the yield point. Then there was a drop in stress or strain softening. Instead of plastic flow and subsequent strain hardening for glassy polymers under compression, in the tensile test, we saw continuous drops in stress with two inflection points. The first inflection occurred when a crack was formed on one edge of the specimen, followed by sub-critical crack growth. The second inflection appeared at the onset of fast crack propagation. The fast crack propagation led to rapid stress drop and eventual fracture of the specimen. In this study, the stress at the first inflection point was used to calculate the healing efficiency of the epoxy.

The experimental results for acquiring the ultimate tensile strengths of the healed specimens are shown in Figure 8b. The healing experimental parameters for the four types of samples are listed in Table 1. We can tell that there is a clear difference in the ultimate tensile strength among the healed specimens with varying healing conditions. When comparing sample 1 and sample 3 , we can see that the higher the compression programming strain, the larger the healing efficiency. When comparing sample 1 and sample 4 , we can conclude that the higher the healing temperature, the greater the healing efficiency. When comparing sample 2 and sample 4, we know that the longer the healing time, the higher the healing efficiency. The reason is that higher compression programming level leads to higher recovery stress, and thus tighter contact between the fracture surfaces, and higher healing efficiency [53]. Both longer healing time and higher healing temperature enhance the transesterification reaction, and thus higher healing efficiency.

\subsection{Discussion of the effect of design parameters on the healing efficiency}

From Table 1, healing temperature $\left(120\right.$ or $\left.150{ }^{\circ} \mathrm{C}\right)$, healing time (18 or $\left.52 \mathrm{~h}\right)$ and programming pre-strain level ( 8.5 or $3.0 \%)$ are the three parameters selected to study their 
influence on the healing efficiency of the material. The two epoxy block specimen surfaces for the healing experiments were not polished for the worst case scenario testing. The reason to choose relatively small programming levels is that the healing process is proceeded at 120 or $150{ }^{\circ} \mathrm{C}$, and we need to ensure that the recovery stress is smaller than the ultimate compressive strength at the healing temperature so that the recovery stress helps close the crack, but not creates new fracture.
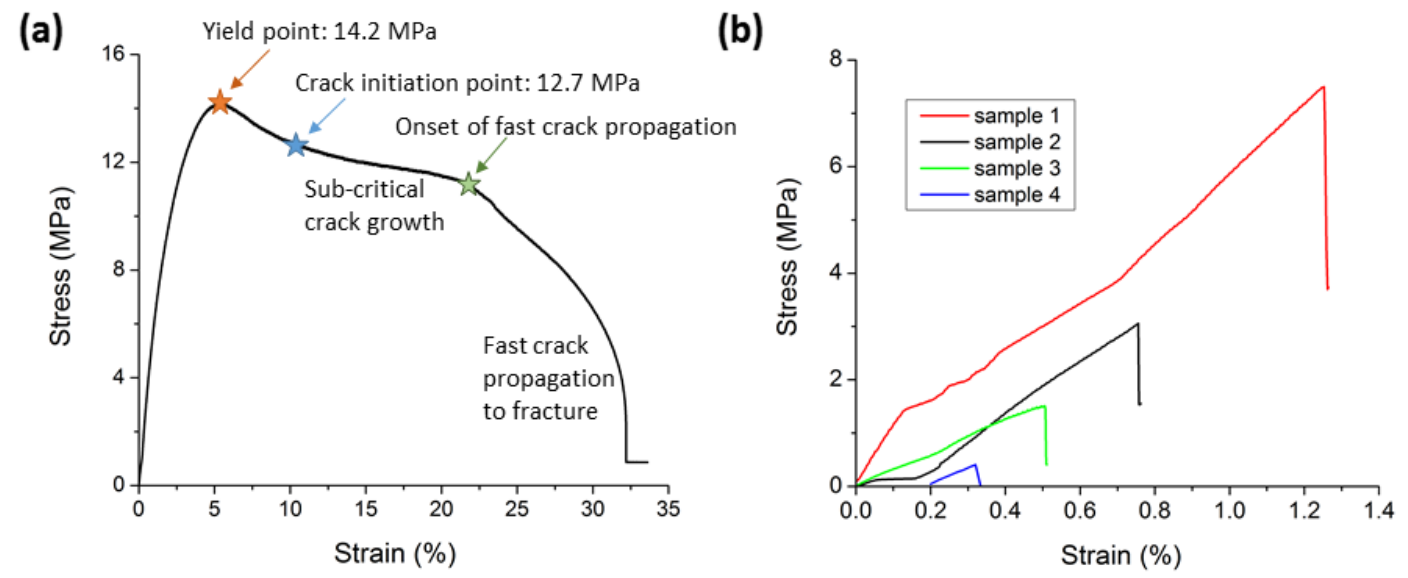

Figure 8. The ultimate tensile strength tests for as-prepared (a) and healed specimen (b). The healing parameters for sample 1 to 4 in Figure $8 \mathrm{~b}$ are listed in Table 1. In Figure 8b, for sample 4, the blue curve offset $0.2 \%$ in the $\mathrm{x}$ axis for better visualization of all curves.

Table 1. Experimental Parameters for Four Sets of Healing Experiments.

\begin{tabular}{cccccc}
\hline Sample & $\begin{array}{c}\text { Healing } \\
\text { temperature } \\
\left({ }^{\circ} \mathrm{C}\right)\end{array}$ & $\begin{array}{c}\text { Healing } \\
\text { time } \\
(\mathrm{h})\end{array}$ & $\begin{array}{c}\text { Compression } \\
\text { programming } \\
(\%)\end{array}$ & $\begin{array}{c}\text { Ultimate } \\
\text { tensile strength } \\
(\mathrm{MPa})\end{array}$ & $\begin{array}{c}\text { Healing } \\
\text { efficiency } \\
(\%)\end{array}$ \\
\hline 1 & 150 & 18 & 8.5 & 7.5 & 59 \\
2 & 120 & 52 & 8.5 & 3.1 & 24 \\
3 & 150 & 18 & 3.0 & 1.5 & 12 \\
4 & 120 & 18 & 8.5 & 0.4 & 3 \\
\hline
\end{tabular}

During the healing process, the changes of stress vs. time was tracked by the MTS machine, where the stacked two epoxy blocks stand. As shown in Figure 9, the scales of the coordinate axis for all figures are set to be the same for ease of comparison. There is a sharp increase in the stress for all four plots as the temperature rises in the MTS oven. The 
peaks were reached when the oven temperatures were around $95-100{ }^{\circ} \mathrm{C}$, followed by a drop in stress. This type of stress recovery behavior is common for cold programmed SMPs [45]. The drop in stress indicates the relaxation of epoxy, which indirectly demonstrates that transesterification reactions take place and healing happens [54,55]. With the transesterification reaction and the re-organization of the material at the fracture surface, the stress increased and reached the second maximum within $1 \mathrm{~h}$ and then kept stable or decreased a little with time. The reason is that the healing gradually increases the stiffness of the specimen, leading to gradual increase in the measured recovery stress. The slight decrease after $1 \mathrm{~h}$ healing time may be due to stress relaxation of the newly formed network. Sample 1 with $150{ }^{\circ} \mathrm{C}$ healing temperature and $8.5 \%$ compression programming has the highest recovery force during healing (Figure 9a). The other three have similar stabilized recovery forces.

As a result of the highest peak recovery stress and stabilized recovery stress, Sample 1 has the highest healing efficiency, followed by Sample 2 and Sample 3, and the lowest by Sample 4. This clearly shows the important role played by the recovery stress during the healing process on the healing efficiency. Higher peak and stabilized recovery stress facilitates crack closure and tight contact between the fracture surfaces, and helps the transesterification reaction, and thus enhances the healing efficiency. Therefore, in practice, measures should be taken to enhance the peak recovery stress, which is affected by pre-strain level, programing temperature, healing temperature, and healing time. Of course, we have to make sure that the recovery stress is lower than the ultimate compressive strength of the specimen at the healing temperature. 
(a)

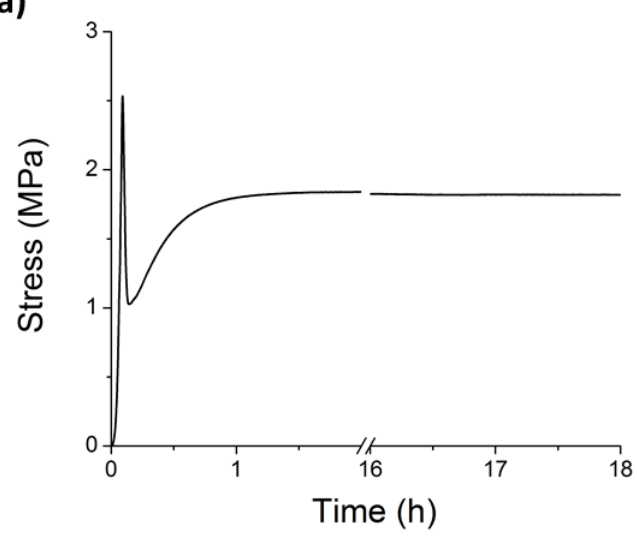

(c)

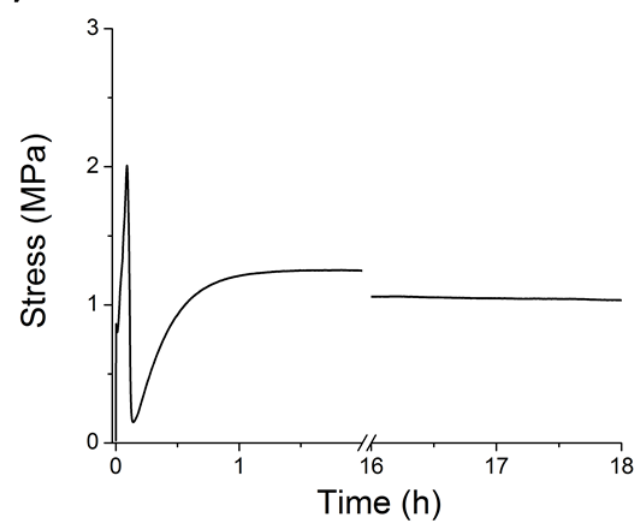

(b)

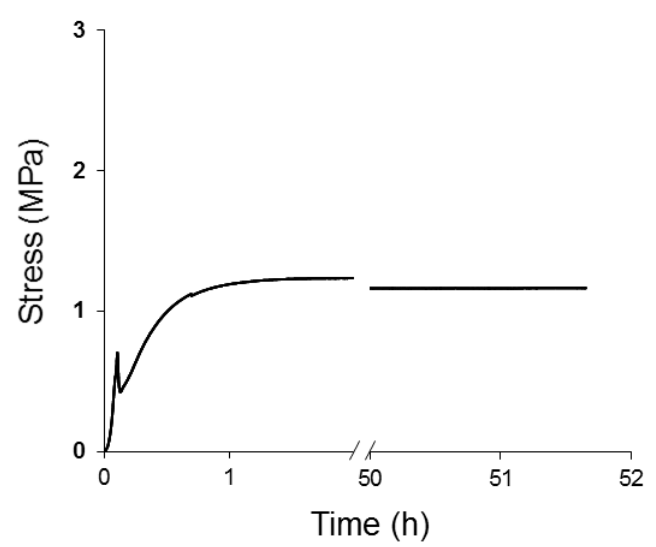

(d)

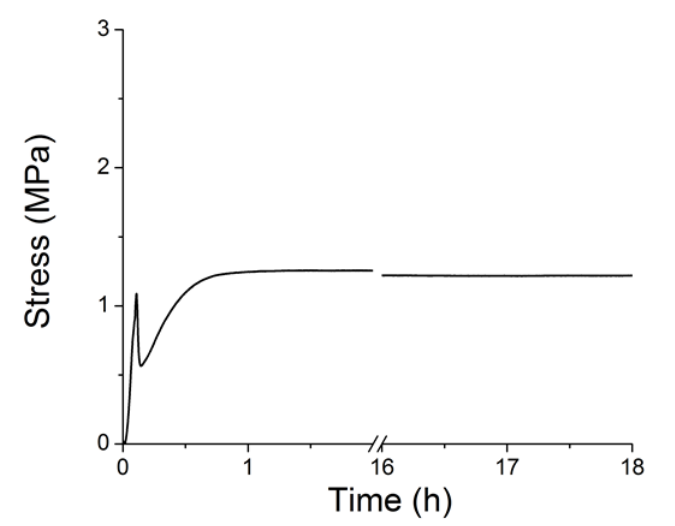

Figure 9. Stresses monitored along with time during the healing process. (a) Sample 1, (b) sample 2, (c) sample 3, and (d) sample 4. The scales of the $\mathrm{z}$ axis are the same for all four figures. There are breaks set on the $\mathrm{x}$ axis so that all the peak features can be visualized.

\section{CONCLUSIONS}

Intrinsic healable and recyclable epoxy was successfully prepared using esterification reaction of diglycidyl ether of bisphenol A (DGEBA) and tricarballylic acid at 1:1 stoichiometry of the epoxide from DGEBA and $-\mathrm{COOH}$ in tricarballylic acid. This epoxy is thermally stable till $380^{\circ} \mathrm{C}$ and has modulus of $1.3 \mathrm{GPa}$ at room temperature. The healing process was achieved by compression programming two saw-cut epoxy block specimens and then stacking them in a confined space at elevated temperatures (120 or $\left.150{ }^{\circ} \mathrm{C}\right)$. The transesterification reaction at the fracture surface induced the healing of the epoxy and the healing efficiency reached $\sim 60 \%$ for the worst case scenario testing (i.e. 
completely cut using band saw and the crack lines were not matched or aligned during healing). It is found that the peak recovery stress or the stabilized recovery stress is an indicator for the healing efficiency. Higher peak recovery stress or stabilized recovery stress leads to higher healing efficiency. Longer healing time also facilitates the transesterification reaction and thus can increases the healing efficiency. The intrinsic healing capability, together with the shape memory effect, makes this thermoset epoxy recyclable when the fractured pieces are contained in a confined space or used in real-world composite structures.

\section{ACKNOWLEDGMENTS}

The authors gratefully acknowledge the financial support by National Science Foundation under grant number CMMI 1333997, NASA cooperative agreement NNX16AQ93A under contract number NASA/LEQSF(2016-19)-Phase3-10, and Army Research Office under grant number W911NF-13-1-0145.

\section{Supporting Information}

The supporting information can be found at: link

Video S1: Shape-memory behavior of the self-healing epoxy.

\section{References}

[1] S. J. Rowan; S. J. Cantrill; G. R. L. Cousins; J. K. M. SAnders; J. F. Stoddart, Dynamic Covalent Chemistry. Angew. Chem., Int. Ed. 41 (2002) 898-952.

[2] H. Otsuka; K. Aotani; Y. Higaki; Y. Amamoto; A. TAKahara, Thermal Reorganization and Molecular Weight Control of Dynamic Covalent Polymers Containing Alkoxyamines in Their Main Chains. Macromolecules 40 (2007) 14291434. 
[3] J.B. LIN; X.N. XU; X.K. JIANG; Z.T. LI, Hydrogen Bonding-Directed Multicomponent Dynamic Covalent Assembly of Mono- and Bimacrocycles. SelfSorting and Macrocycle Exchange. J. Org. Chem. 73 (2008) 9403-9410.

[4] B. J. Adzima; H. A. Aguirre; C. J. Kloxin; T. F. Scott; C. N. Bowman, Rheological and Chemical Analysis of Reverse Gelation in a Covalently CrossLinked Diels-Alder Polymer Network. Macromolecules 41 (2008) 9112-9117.

[5] J. Y. Chang; S. K. Do; M. J. Han, A Sol-Gel Reaction of Vinyl Polymers Based on Thermally Reversible Urea Linkages. Polymer 42 (2001) 7589-7594.

[6] J. W. Kamplain; C. W. Bielawski, Dynamic Covalent Polymers Based Upon Carbene Dimerization. Chem. Commun. (2006) 1727-1729.

[7] R. J. Wojtecki; M. A. Meador; S. J. Rowan, Using the Dynamic Bond to Access Macroscopically Responsive Structurally Dynamic Polymers. Nat. Mater. 10 (2011) $14-27$.

[8] C. N. Bowman; C. J. Kloxin, Covalent Adaptable Networks: Reversible Bond Structures Incorporated in Polymer Networks. Angew. Chem., Int. Ed. 51 (2012) 4272-4274.

[9] R. LonG; H. J. QI; M. L. DunN, Modeling the Mechanics of Covalently Adaptable Polymer Networks with Temperature-Dependent Bond Exchange Reactions. Soft Matter 9 (2013) 4083-4096.

[10] I. A. Rousseau; P. T. Mather, Shape Memory Effect Exhibited by Smectic-C Liquid Crystalline Elastomers. J. Am. Chem. Soc. 125 (2003) 15300-15301. 
[11] C. J. Kloxin; T. F. ScotT; B. J. Adzima; C. N. Bowman, Covalent Adaptable Networks (Cans): A Unique Paradigm in Cross-Linked Polymers. Macromolecules 43 (2010) 2643-2653.

[12] X. Chen; M. A. DAM; K. OnO; A. MAL; H. Shen; S. R. NutT; K. Sheran; F. WUdL, A Thermally Re-Mendable Cross-Linked Polymeric Material. Science 295 (2002) $1698-1702$.

[13] T. XIE; I. A. RousseaU, Facile Tailoring of Thermal Transition Temperatures of Epoxy Shape Memory Polymers. Polymer 50 (2009) 1852-1856.

[14] T. TanPITAKsit; C. JubSilP; S. Rimdusit, Effects of Benzoxazine Resin on Property Enhancement of Shape Memory Epoxy: A Dual Function of Benzoxazine Resin as a Curing Agent and a Stable Network Segment. eXPRESS Polym. Lett. 9 (2015) 824-837.

[15] Z. Pei; Y. YanG; Q. ChEN; Y. WeI; Y. Ji, Regional Shape Control of Strategically Assembled Multishape Memory Vitrimers. Adv. Mater. 28 (2016) 156-160.

[16] I. A. Rousseau; T. XIE, Shape Memory Epoxy: Composition, Structure, Properties and Shape Memory Performances. J. Mater. Chem. 20 (2010) 3431-3441.

[17] S. R. White; N. R. Sottos; P. H. Geubelle; J. S. Moore; M. R. Kessler; S. R. SRIRAM; E. N. Brown; S. Viswanathan, Autonomic Healing of Polymer Composites. Nature 409 (2001) 794-797.

[18] J. D. RulE; E. N. BRown; N. R. Sottos; S. R. White; J. S. Moore, Wax-Protected Catalyst Microspheres for Efficient Self-Healing Materials. Adv. Mater. 17 (2005) 205-208. 
[19] P. A. Pratama; M. Sharifi; A. M. Peterson; G. R. PalmeSe, Room Temperature Self-Healing Thermoset Based on the Diels-Alder Reaction. ACS Appl. Mater. Interfaces 5 (2013) 12425-12431.

[20] E. N. BRown; S. R. WhITE; N. R. SOTtos, Retardation and Repair of Fatigue Cracks in a Microcapsule Toughened Epoxy Composite—Part Ii: In Situ Self-Healing. Compos. Sci. Technol. 65 (2005) 2474-2480.

[21] T. YIN; M. Z. RonG; M. Q. ZHANG; G. C. YANG, Self-Healing Epoxy Composites Preparation and Effect of the Healant Consisting of Microencapsulated Epoxy and Latent Curing Agent. Compos. Sci. Technol. 67 (2007) 201-212.

[22] Y. C. Yuan; M. Z. Rong; M. Q. Zhang; J. Chen; G. C. YANG; X. M. LI, SelfHealing Polymeric Materials Using Epoxy/Mercaptan as the Healant. Macromolecules 41 (2008) 5197-5202.

[23] Y. C. Yuan; X. J. Ye; M. Z. RonG; M. Q. ZhanG; G. C. YANG; J. Q. ZhaO, SelfHealing Epoxy Composite with Heat-Resistant Healant. ACS Appl. Mater. Interfaces 3 (2011) 4487-4495.

[24] C. L. Mangun; A. C. Mader; N. R. Sottos; S. R. White, Self-Healing of a High Temperature Cured Epoxy Using Poly(Dimethylsiloxane) Chemistry. Polymer 51 (2010) 4063-4068.

[25] H. Jin; C. L. Mangun; D. S. StRadley; J. S. Moore; N. R. Sottos; S. R. White, Self-Healing Thermoset Using Encapsulated Epoxy-Amine Healing Chemistry. Polymer 53 (2012) 581-587. 
[26] R. WANG; H. LI; H. Hu; X. HE; W. LIU, Preparation and Characterization of SelfHealing Microcapsules with Poly(Urea-Formaldehyde) Grafted Epoxy Functional Group Shell. J. Appl. Polym. Sci. 113 (2009) 1501-1506.

[27] D. S. XIAO; Y. C. YuAN; M. Z. RonG; M. Q. ZHANG, Self-Healing Epoxy Based on Cationic Chain Polymerization. Polymer 50 (2009) 2967-2975.

[28] E. L. Kirkby; V. J. Michaud; J. A. E. MÅnson; N. R. Sottos; S. R. White, Performance of Self-Healing Epoxy with Microencapsulated Healing Agent and Shape Memory Alloy Wires. Polymer 50 (2009) 5533-5538.

[29] T. S. CoOPE; U. F. J. MAYeR; D. F. WASS; R. S. TRASK; I. P. Bond, Self-Healing of an Epoxy Resin Using Scandium(Iii) Triflate as a Catalytic Curing Agent. Adv. Funct. Mater. 21 (2011) 4624-4631.

[30] X. LiU; H. Zhang; J. Wang; Z. Wang; S. Wang, Preparation of Epoxy Microcapsule Based Self-Healing Coatings and Their Behavior. Surf. Coat. Technol. 206 (2012) 4976-4980.

[31] K. R. HART; N. R. Sottos; S. R. WhitE, Repeatable Self-Healing of an Epoxy Matrix Using Imidazole Initiated Polymerization. Polymer 67 (2015) 174-184.

[32] M. M. Caruso; D. A. Delafuente; V. Ho; N. R. Sottos; J. S. Moore; S. R. White, Solvent-Promoted Self-Healing Epoxy Materials. Macromolecules 40 (2007) 88308832.

[33] Y. YongtaO; W. JingJie; L. HaibaO; X. Ben; F. YongQInG; L. Yanju; L. Jinsong, Thermosetting Epoxy Resin/Thermoplastic System with Combined Shape Memory and Self-Healing Properties. Smart Mater. Struct. 25 (2016) 015021. 
[34] D. Montarnal; M. CAPelot; F. TournilhaC; L. LeIBLER, Silica-Like Malleable Materials from Permanent Organic Networks. Science 334 (2011) 965-968.

[35] M. Capelot; D. Montarnal; F. Tournilhac; L. Leibler, Metal-Catalyzed Transesterification for Healing and Assembling of Thermosets. J. Am. Chem. Soc. 134 (2012) 7664-7667.

[36] P. TAYnton; H. Ni; C. ZhU; K. YU; S. LoOB; Y. Jin; H. J. QI; W. ZhANG, Repairable Woven Carbon Fiber Composites with Full Recyclability Enabled by Malleable Polyimine Networks. Adv. Mater. 28 (2016) 2904-2909.

[37] Y. MenG; J. JiAnG; M. ANTHAMATtEN, Shape Actuation Via Internal Stress-Induced Crystallization of Dual-Cure Networks. ACS Macro Lett. 4 (2015) 115-118.

[38] K. Yu; P. TAYnton; W. Zhang; M. L. DunN; H. J. QI, Reprocessing and Recycling of Thermosetting Polymers Based on Bond Exchange Reactions. RSC Adv. 4 (2014) 10108-10117.

[39] H. YanG; K. Yu; X. Mu; Y. WeI; Y. Guo; H. J. QI, Molecular Dynamics Studying on Welding Behavior in Thermosetting Polymers Due to Bond Exchange Reactions. RSC Adv. 6 (2016) 22476-22487.

[40] G. LI, Self-Healing Composites: Shape Memory Polymer Based Structures. John Wiley \& Sons, Inc., West Sussex, UK. (2014).

[41] G. LI; N. UpPU, Shape Memory Polymer Based Self-Healing Syntactic Foam: 3-D Confined Thermomechanical Characterization. Compos. Sci. Technol. 70 (2010) $1419-1427$.

[42] G. Li; D. NetTles, Thermomechanical Characterization of a Shape Memory Polymer Based Self-Repairing Syntactic Foam. Polymer 51 (2010) 755-762. 
[43] L. MatejKa; S. Pokorny; K. DuseK, Network Formation Involving Epoxide and Carboxyl Groups - Course of the Model Reaction Monoepoxide-Monocarbonic Acid. Polym. Bull. 7 (1982) 123-128.

[44] K. YU; Q. Shi; H. Li; J. JabouR; H. YanG; M. L. DunN; T. WanG; H. J. QI, Interfacial Welding of Dynamic Covalent Network Polymers. J. Mech. Phys. Solids 94 (2016) 1-17.

[45] G. LI; W. XU, Thermomechanical Behavior of Thermoset Shape Memory Polymer Programmed by Cold-Compression: Testing and Constitutive Modeling. J. Mech. Phys. Solids 59 (2011) 1231-1250.

[46] G. Li; O. AJISAFE; H. Meng, Effect of Strain Hardening of Shape Memory Polymer Fibers on Healing Efficiency of Thermosetting Polymer Composites. Polymer 54 (2013) 920-928.

[47] G. LI; M. JoHN, A Self-Healing Smart Syntactic Foam under Multiple Impacts. Compos. Sci. Technol. 68 (2008) 3337-3343.

[48] M. JoHN; G. LI, Self-Healing of Sandwich Structures with Grid Stiffened Shape Memory Polymer Syntactic Foam Core. Smart Mater. Struct. 19 (2010) 075013.

[49] J. NJI; G. LI, A Self-Healing 3D Woven Fabric Reinforced Shape Memory Polymer Composite for Impact Mitigation. Smart Mater. Struct. 19 (2010) 035007.

[50] G.O. Wilson; M.M. CARuso; N.T. ReIMER; S.R. White; N.R. SotTos; J.S. MoORE, Evaluation of Ruthenium Catalysts for Ring-Opening Metathesis PolymerizationBased Self-Healing Applications. Chem. Mater. 20 (2008) 3288-3297.

[51] J. NJi; G. LI, A Biomimic Shape Memory Polymer Based Self-Healing Particulate Composite. Polymer 51 (2010) 6021-6029. 
[52] J. NJI; G. LI, Damage Healing Ability of a Shape-Memory-Polymer-Based Particulate Composite with Small Thermoplastic Contents. Smart Mater. Struct. 21 (2012) 025011.

[53] A. SHOJAEI; S. SHARAFI; and G. LI, A Multiscale Theory of Self-Crack-Healing with Solid Healing Agent Assisted by Shape Memory Effect. Mech. Mater. 81 (2015) $25-40$.

[54] F. SniJKers; R. PASQuino; A. MAFFEZZOLI, Curing and Viscoelasticity of Vitrimers. Soft Matter (2016) DOI: 10.1039/C6SM00707D.

[55] E. B. Stukalin; L.-H. CaI; N. A. Kumar; L. LeibleR; M. Rubinstein, Self-Healing of Unentangled Polymer Networks with Reversible Bonds. Macromolecules 46 (2013) 7525-7541. 


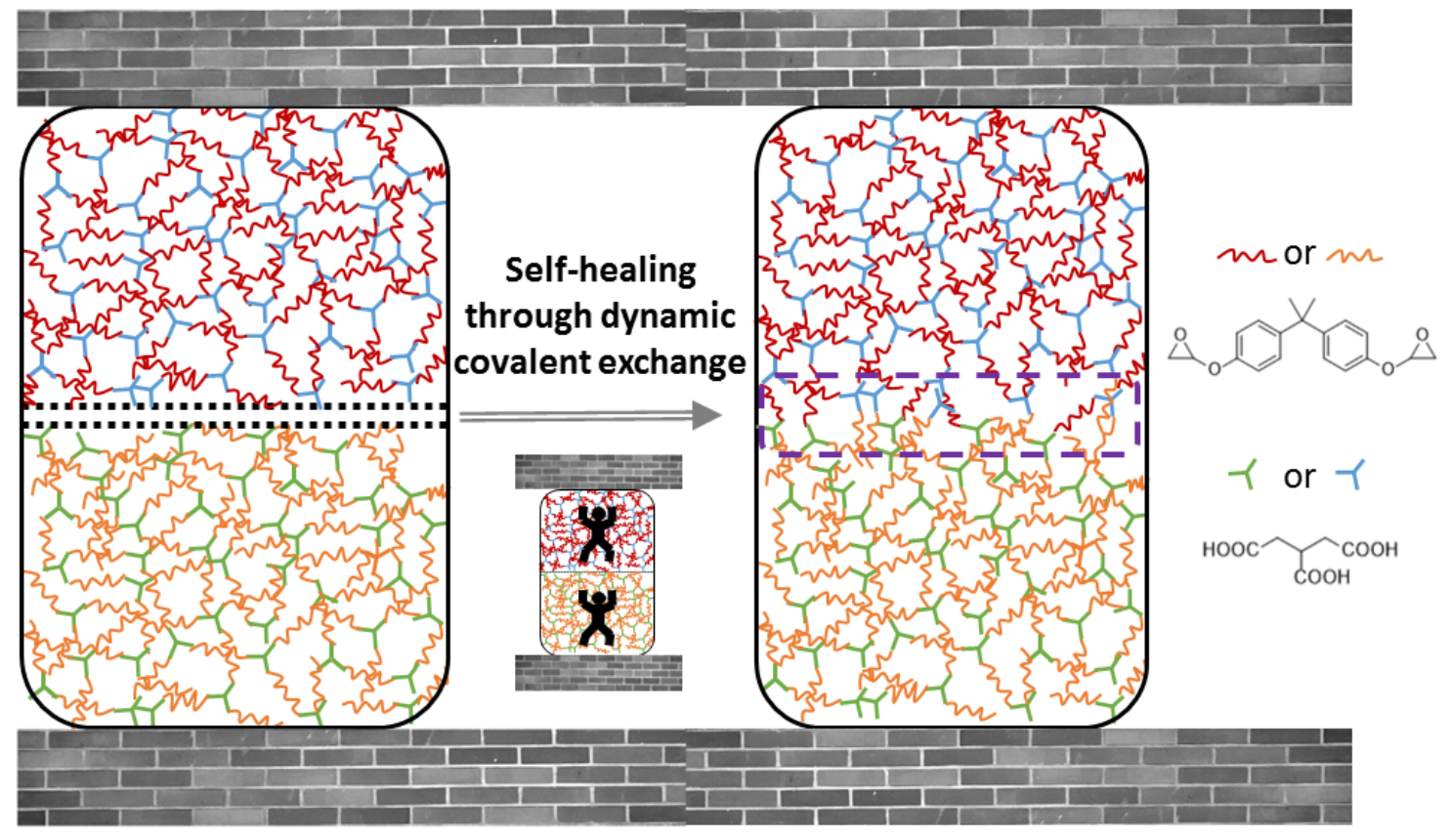

